\title{
Maternal low protein diet in rats programmes fatty acid desaturase activities in the offspring
}

\author{
S.E. Ozanne, N. D. Martensz, C. J. Petry, C.L Loizou, C. N. Hales \\ Department of Clinical Biochemistry, University of Cambridge, Addenbrooke's Hospital, Cambridge, UK
}

\begin{abstract}
Summary Numerous studies show an association between poor fetal growth and adult insulin resistance. Recent studies have shown relation between the long chain polyunsaturated fatty acid composition of skeletal muscle membranes and insulin sensitivity. More detailed analysis has indicated that the activity of $\Delta 5$ desaturase is inversely correlated to insulin resistance. The amount of docosahexaenoic acid $(\mathrm{C} 22: 6 \mathrm{n} 3)$ is also thought to play a part in determining insulin sensitivity. The purpose of this study was to test the hypothesis that early growth retardation in the rat, as a result of maternal protein restriction, would lead to alterations in desaturase activities similar to those observed in human insulin resistance. There were no differences in phospholipid fatty acid composition in liver or muscle from control and low
\end{abstract}

protein rats. In both muscle and liver the ratio of docosahexaenoic acid to docosapentaenoic acid was, however, reduced in low protein offspring. Direct measurement of $\Delta 5$ desaturase activity in hepatic microsomes showed a reduction $(p<0.03)$ in the low protein offspring which was negatively corrrelated $(r=-0.855)$ with fasting plasma insulin. No correlation was observed in controls. These results show that it is possible to programme the activity of key enzymes involved in the desaturation of long chain polyunsaturated fatty acids. This is possibly a mechanism linking fetal growth retardation to insulin resistance. [Diabetologia (1998) 41: 1337-1342]

Keywords Insulin resistance, fetal growth, non-insulin-dependent diabetes mellitus, desaturase activity.
Insulin resistance is an important feature of impaired glucose tolerance (IGT) or Type II (non-insulin-dependent) diabetes mellitus [1]. The biochemical site(s) of this defect are not defined. Recent studies have shown that there is a strong relation between muscle phospholipid fatty acid composition and whole body insulin sensitivity [2]. Polyunsaturated fatty acids are synthesized through a series of elongation and desaturation reactions (Fig.1). From an analysis of the relative proportions of the precursor

Received: 25 March 1998 and in final revised form: 17 June 1998

Corresponding author: Dr. S. E. Ozanne, Department of Clinical Biochemistry, Addenbrooke's Hospital, Hills Road, Cambridge CB2 2QR, UK

Abbreviations: IGT, Impaired glucose tolerance; PG, prostaglandin. and product of $\Delta 5$ desaturase, it has been deduced that changes in the long chain fatty acid composition of phospholipids associated with insulin resistance reflects a defect of action of this enzyme [3]. In addition it has been noted that Pima Indians (a population with a high prevalence of Type II diabetes) have relatively low levels of docosahexaenoic acid (22:6n-3) compared with populations with lower prevalences of Type II diabetes. It has therefore been suggested that a defect in the synthesis or activity of this enzyme could contribute to a genetic basis of Type II diabetes [3].

Epidemiological studies have shown strong relations between indices of poor fetal and infant growth and the subsequent risk of developing IGT, Type II diabetes or the insulin resistance syndrome [4]. It has been hypothesised that poor fetal nutrition induces permanent changes in the structure and function of key organs such that poor insulin secretion and insu- 
Biosynthesis of polyunsaturated fatty acids

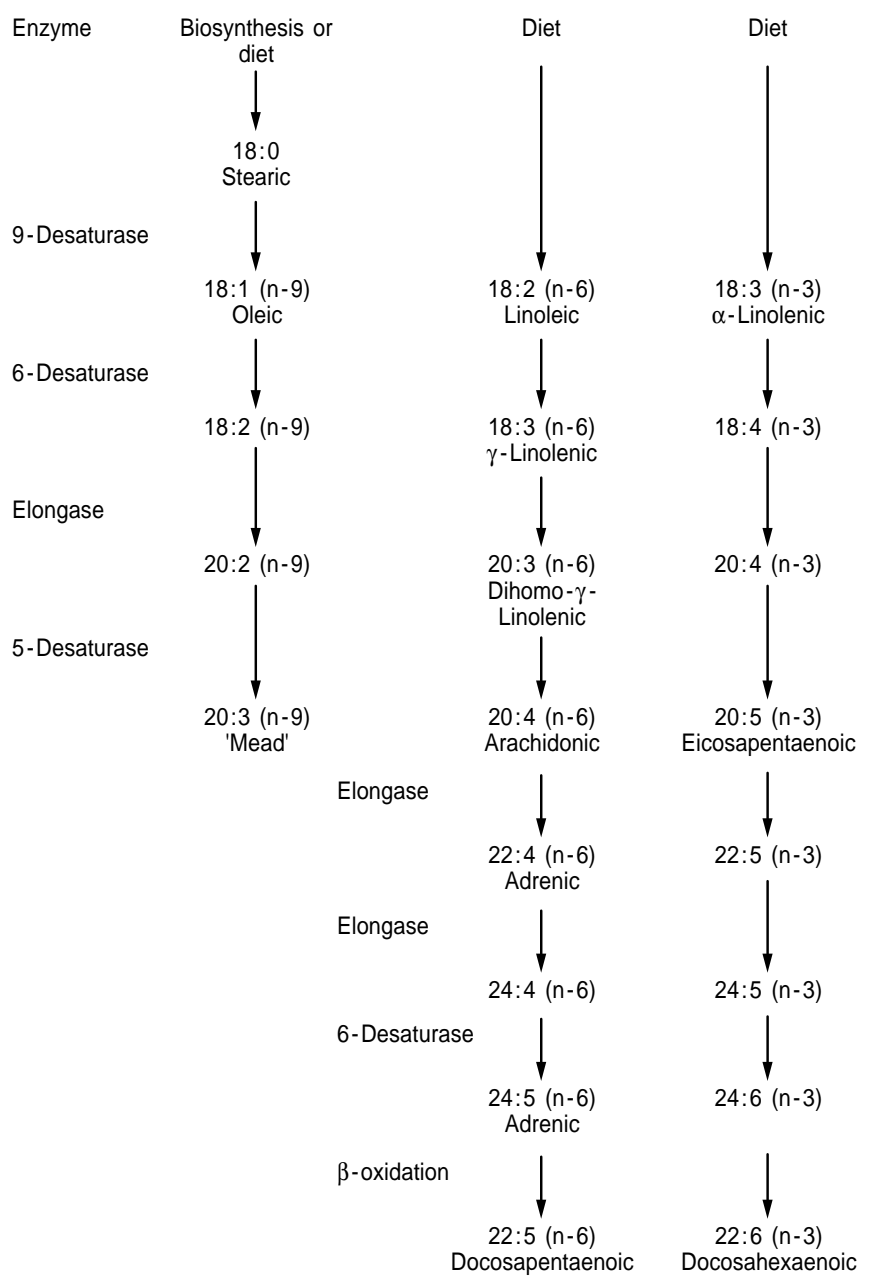

Fig. 1. The elongation and desaturation of the n-6 and n-3 families of fatty acids

lin resistance are manifested in adult life [5]. These changes, plus adult obesity, strongly predispose to IGT, Type II diabetes and the insulin resistance syndrome. The possible key role of protein deficiency during pregnancy in this process was indicated [5]. In a rat model of protein deficiency during pregnancy and lactation we have shown that the action of insulin on the liver is altered in the offspring [6]. In this model rats are fed either an $8 \%$ (low protein) or an isocaloric $20 \%$ (control) protein diet during pregnancy and lactation. All offspring are then weaned onto a control diet. Although in young adult life the low protein offspring exhibit a better glucose tolerance than controls [7], they undergo a greater age-dependent loss of glucose tolerance than controls such that by 15 months of age low protein offspring have a significantly worse glucose tolerance [7].

It has been observed that the offspring of rat dams fed very low protein diets and weaned onto such a diet for a further 10 days had reduced hepatic $\Delta 5$, $\Delta 6$ and $\Delta 9$ desaturase activity [8]. This study, howev- er, did not investigate if the reduction in these activities was maintained after introduction of a normal diet.

The aim was to determine if protein deficiency during pregnancy and early post natal life could permanently reduce ("programme") the activity of the hepatic $\Delta 5$ and $\Delta 6$ desaturase enzymes and if so, how this could be related to the fatty acid composition of liver and muscle phospholipids. It was also determined whether hepatic desaturase activities and phospholipid fatty acid composition were associated with whole body insulin sensitivity (as measured by the fasting insulin concentration) in control and low protein offspring at 3 months of age.

\section{Materials and methods}

Analytical grade biochemicals were obtained from Sigma Chemical Co. or BDH biochemicals (both of Poole, Dorset, UK), unless stated otherwise. $\left[1-{ }^{14} \mathrm{C}\right]$ 8, 11,14 eicosatrienoic acid $(47 \mathrm{mCi} / \mathrm{mmol})\left({ }^{14} \mathrm{C}-20: 3 \mathrm{n}-6\right)$ was obtained from $\mathrm{NEN}-$ DuPont, UK. $\left[1-{ }^{14} \mathrm{C}\right]$ arachidonic acid $(50 \mathrm{mCi} / \mathrm{mmol})\left({ }^{14} \mathrm{C}-\right.$ $20: 4 \mathrm{n} 6)$ and $\left[1{ }^{14} \mathrm{C}\right]$ linoleic acid $(59 \mathrm{mCi} / \mathrm{mmol})\left({ }^{14} \mathrm{C}-18: \mathrm{n}-6\right)$ were obtained from Amersham, UK.

Animals. Female Wistar rats (initial weight 240 to $260 \mathrm{~g}$ ) were fed either a diet containing $20 \%$ protein $(n=4)$ or an isocalorific diet containing $8 \%$ protein $(n=4)$ (both diets obtained from Hoppe Farms BV, Hoge Rijndijk14, 3440 HD Woerden, The Netherlands) throughout pregnancy and lactation. At 21 days of age all offspring were weaned onto a $20 \%$ protein diet (Special Diet Services, Witham, UK). For simplicity the two groups of offspring are termed "control" and "low protein", however it is emphasised that only the mothers undergo dietary manipulation. All rats studied were male and 3 months of age ( $n=8$ control offspring and $n=8$ low protein offspring). They were starved overnight $(18 \mathrm{~h})$ prior to commencement of procedures.

Blood sampling and insulin assay. Animals were anaesthetised with an intraperitoneal injection of sodium pentobarbital (50 mg/kg body weight), blood was removed immediately from the tail vein for glucose (Gamidor, Abingdon, UK) and insulin measurement (Linco rat insulin radioimmunoassay kit, Biogenesis, Poole, UK).

Tissue collection. Tibialis anterior muscle was removed and frozen immediately in liquid nitrogen. Samples $(0.4 \mathrm{~g})$ were stored at $-70^{\circ} \mathrm{C}$ prior to analysis. The liver was removed and placed into ice-cold homogenization buffer $(0.25 \mathrm{~mol} / \mathrm{l} \mathrm{su}-$ crose, $1 \mathrm{mmol} / \mathrm{l}$ dithiothreitol, $1 \mathrm{mmol} / \mathrm{l}$ disodium EDTA, $0.1 \mathrm{~mol} / \mathrm{l}$ potassium dihydrogen orthophosphate, $\mathrm{pH}$ 7.2).

Microsome preparation. Hepatic microsomes were prepared according to a published method [9]. In brief, livers were excised, weighed and rinsed in ice-cold homogenisation buffer. Tissue was minced finely on an ice-cold petri dish and homogenised with buffer (5 volumes) and centrifuged for $10 \mathrm{~min}$ at $800 \times g$. The supernatant was centrifuged for $20 \mathrm{~min}$ at $15000 \times g$. The microsomal pellet was obtained by further centrifugation of the supernatant at $105000 \times g$ for $60 \mathrm{~min}$. Membranes were resuspended in homogenisation buffer, their protein content determined and then stored at $-70^{\circ} \mathrm{C}$. 
Muscle membrane and hepatic microsome phospholipid fatty acid analysis. Extraction and derivatization of the fatty acid components of liver microsome and muscle phospholipids was done as described previously [2,3]. In brief, liver microsomes $(20 \mathrm{mg}$ protein $)$ and muscle tissue $(0.4 \mathrm{~g})$ were homogenized in 2:1 (vol/vol) chloroform:methanol and total lipid extracts prepared according to Folch et al. [10]. Phospholipids were separated from less polar lipids by solid-phase extraction on Sep Pak silica cartridges (Millipore, Watford, UK). The phospholipids were transmethylated using boron trifluoride and the fatty acid methyl esters isolated on Sep Pak florisil cartridges, identified and quantitated by gas liquid chromatography on a Unicam 610 gas chromatograph using a Supelco SP2380 column $(30 \mathrm{~m} \times 0.53 \mathrm{~mm}$. i.d.) with flame ionization detection (column temperature increased from $90-200^{\circ} \mathrm{C}$ at $2^{\circ} \mathrm{C} / \mathrm{min}$ ).

Desaturase assays. The activity of $\Delta 6$ and $\Delta 5$ desaturases were assayed according to a published method [9] using $\left[1-{ }^{14} \mathrm{C}\right]$ labelled linoleic acid (18:2n-6) and eicosatrienoic acid (20:3n-6) fatty acids as their respective substrates. After reaction, fatty acids were saponified, transmethylated and spotted onto $10 \%$ silver nitrate-impregnated silica gel thin-layer chromatography plates (Merck, Darmstadt, Germany) with known standards. Plates were developed in toluene:acetonitrile (97.5:2.5) and radio-labelled products identified by autoradiography and quantified by liquid scintillation counting.

Statistical analysis. Data were analysed using Student's unpaired $t$-test and linear regression analysis, or the non-parametric Mann Whitney U test and Spearman Rank correlation where appropriate (Statistica statistical software, StatSoft (UK) Ltd., Letchworth, UK). Results in all cases are given as mean \pm SEM, together with the absolute probability $(p)$ value and correlation coefficients. A $p$ value of less than 0.05 was considered statistically significant.

\section{Results}

Animal data. Low protein offspring had a lower body weight $(p<0.005)$ than control animals [mean body weights of $422 \pm 18 \mathrm{~g}(n=8)$ and $536 \pm 29 \mathrm{~g}(n=8)$, respectively]. This was also reflected in a reduction $(p<0.001)$ in the size of the liver $[16.6 \pm 0.5 \mathrm{~g}(n=$ $8)]$ in low protein animals compared with controls $[21.0 \pm 0.9 \mathrm{~g} \quad(n=8)]$. There were no differences in fasting blood glucose concentrations (5.5 \pm $0.3 \mathrm{mmol} / 1$ and $6.0 \pm 0.2 \mathrm{mmol} / 1$ in low protein and control animals, respectively).

Desaturase activities. Hepatic microsomes prepared from low protein offspring had less $(p<0.03) \Delta 5$-desaturase activity compared with controls $(100 \pm 13$ $\mathrm{pmol} \cdot \mathrm{mg}$ protein ${ }^{-1} \cdot \mathrm{min}^{-1}$ compared with $145 \pm 13$ $\mathrm{pmol} \cdot \mathrm{mg}$ protein $\left.{ }^{-1} \cdot \mathrm{min}^{-1}\right)$. In contrast there were no differences in hepatic $\Delta 6$-desaturase activity in the two groups $\left(100 \pm 17 \mathrm{pmol} \cdot \mathrm{mg}\right.$ protein ${ }^{-1} \cdot \mathrm{min}^{-1}$ and $113 \pm 23 \mathrm{pmol} \cdot \mathrm{mg}$ protein ${ }^{-1} \cdot \mathrm{min}^{-1}$ for low protein and control).

Plasma insulin and relationship to desaturase activities. There were no significant differences in fasting
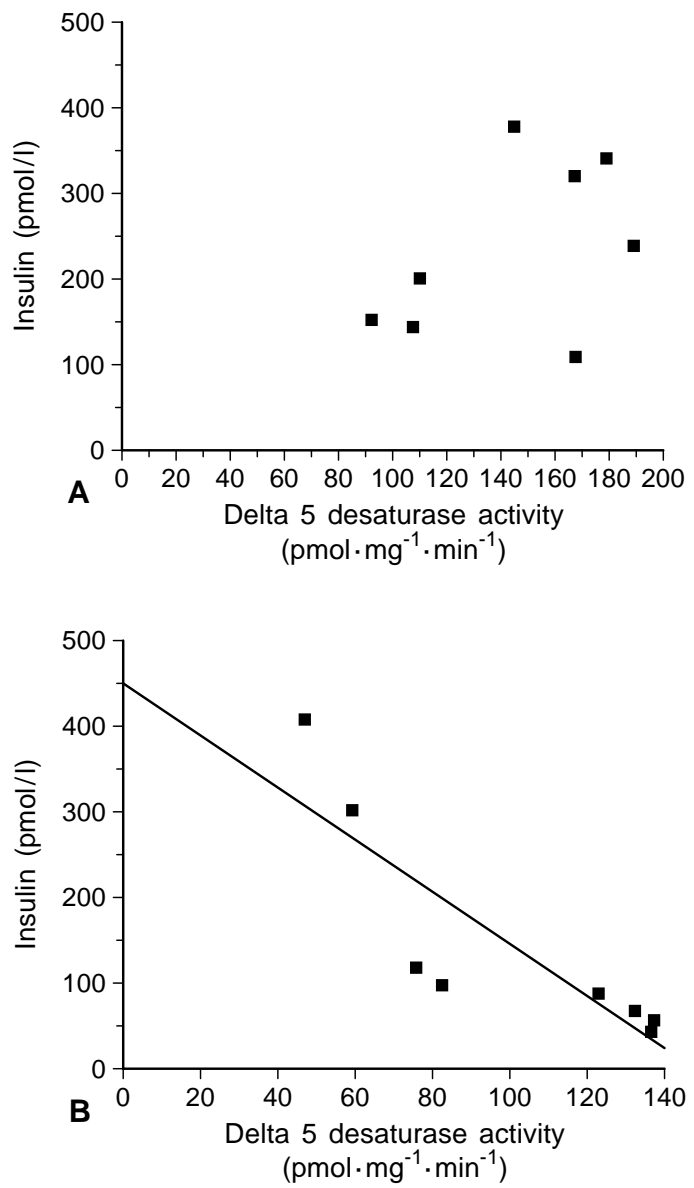

Fig. $2 \mathrm{~A}, \mathbf{B}$. The relation between fasting plasma insulin and hepatic $\Delta 5$ desaturase activity in $(\mathbf{A})$ control and (B) low protein offspring

plasma insulin concentrations in low protein animals and controls $(147 \pm 47 \mathrm{pmol} / \mathrm{l}$ and $236 \pm 35 \mathrm{pmol} / \mathrm{l}$ for low protein and control, respectively). There was, however, a pronounced difference in the relation between fasting plasma insulin concentration and hepatic microsomal $\Delta 5$-desaturase activities. There was no correlation between hepatic $\Delta 5$-desaturase activity and fasting plasma insulin concentrations in control animals (linear regression: $r=0.452, p=0.257$, $n=8$; Spearman rank: $r_{\mathrm{S}}=0.395, p=0.333$ ) (Fig. 2). There was, however, a strong negative correlation between hepatic $\Delta 5$-desaturase activity and fasting plasma insulin concentrations in low protein animals (linear regression: $r=-0.855, p<0.007, n=8$; Spearman rank: $r_{\mathrm{S}}=-0.976, p<0.001$ ) (Fig. 2 ). No correlation was observed between hepatic $\Delta 6$-desaturase activity and fasting plasma insulin concentration in either control or low protein animals.

Fatty acid composition of the weaning diet. The weaning diet contained the long chain polyunsaturated fatty acids arachidonic acid (20:4n-6) and clupanodonic acid (22:5n-3) which were absent in the maternal diet. All diets contained the essential fatty acids 
Table 1. Fatty acid composition of pregnancy and weaning diets ( $\mathrm{g}$ fatty acid/100 g diet)

\begin{tabular}{|c|c|c|c|}
\hline & $\begin{array}{l}20 \% \\
\text { protein }\end{array}$ & $\begin{array}{l}8 \% \\
\text { protein }\end{array}$ & $\begin{array}{l}\text { Weaning } \\
\text { diet }\end{array}$ \\
\hline \multicolumn{4}{|l|}{ Saturated } \\
\hline Lauric (12:0) & 0 & 0 & 0.05 \\
\hline Myristic (14:0) & 0 & 0 & 0.13 \\
\hline Palmitic (16:0) & 0.447 & 0.447 & 0.25 \\
\hline Stearic $(18: 0)$ & 0 & 0 & 0.02 \\
\hline \multicolumn{4}{|l|}{ Monounsaturated } \\
\hline Myristoleic (14:1) & 0 & 0 & 0.04 \\
\hline Palmitoleic (16:1) & 0 & 0 & 0.27 \\
\hline Oleic $(18: 1 n-9)$ & 0.894 & 0.894 & 0.86 \\
\hline \multicolumn{4}{|l|}{ Polyunsaturated } \\
\hline Linoleic $(18: 2 n-6)$ & 2.195 & 2.195 & 0.71 \\
\hline$\alpha$-Linolenic (18:3n-3) & 0.325 & 0.325 & 0.08 \\
\hline Arachidonic $(20: 4 n-6)$ & 0 & 0 & 0.23 \\
\hline Clupanodonic (22:5n-3) & 0 & 0 & 0.06 \\
\hline
\end{tabular}

Values are provided by the manufacturers

Table 2. Fatty acid composition of liver microsome phospholipids

\begin{tabular}{lcc}
\hline Fatty acid & $\begin{array}{l}\text { Control } \\
\text { (\% composition) }\end{array}$ & $\begin{array}{l}\text { Low protein } \\
\text { (\% composition) }\end{array}$ \\
\hline C16:0 & $23.1 \pm 0.7$ & $22.8 \pm 0.8$ \\
C18:0 & $18.5 \pm 1.7$ & $18.3 \pm 2.0$ \\
C18:1 (n-9) & $3.2 \pm 0.7$ & $4.9 \pm 0.8$ \\
C18:2(n-6) & $11.7 \pm 0.6$ & $12.2 \pm 0.4$ \\
C20:3(n-6) & $1.30 \pm 0.1$ & $1.31 \pm 0.12$ \\
C20:4 (n-6) & $25.7 \pm 0.9$ & $23.5 \pm 1.0$ \\
C20:5 (n-3) & $1.2 \pm 0.1$ & $1.4 \pm 0.2$ \\
C22:5(n-3) & $1.4 \pm 0.2$ & $1.7 \pm 0.1$ \\
C22:6(n-3) & $12.2 \pm 0.7$ & $10.8 \pm 0.6$ \\
$\Delta 5$ ratio & $20.4 \pm 1.5$ & $21.0 \pm 2.1$ \\
$22: 6 n-3 / 22: 5 n-3$ & $9.1 \pm 0.8$ & $6.9 \pm 0.5^{\mathrm{a}}$ \\
\hline
\end{tabular}

${ }^{\mathrm{a}} p<0.05$

Table 3. Fatty acid composition of muscle phospholipids

\begin{tabular}{lcc}
\hline Fatty acid & $\begin{array}{l}\text { Control } \\
\text { (\% composition) }\end{array}$ & $\begin{array}{l}\text { Low protein } \\
\text { (\% composition) }\end{array}$ \\
\hline C16:0 & $21.3 \pm 3.2$ & $21.0 \pm 2.2$ \\
C18:0 & $10.2 \pm 1.3$ & $10.6 \pm 0.8$ \\
C18:1 (n-9) & $7.6 \pm 1.1$ & $8.3 \pm 0.5$ \\
C18:2(n-6) & $16.0 \pm 0.9$ & $16.5 \pm 0.6$ \\
C20:3 (n-6) & $0.6 \pm 0.1$ & $0.7 \pm 0.1$ \\
C20:4 (n-6) & $7.8 \pm 0.5$ & $7.9 \pm 0.5$ \\
C20:5 (n-3) & $0.8 \pm 0.1$ & $0.9 \pm 0.1$ \\
C22:5 (n-3) & $2.4 \pm 0.2$ & $2.7 \pm 0.2$ \\
C22:6 (n-3) & $17.0 \pm 1.2$ & $16.3 \pm 0.9$ \\
$\Delta 5$ ratio & $12.6 \pm 0.2$ & $12.1 \pm 1.0$ \\
22:6n3/22:5n3 & $7.2 \pm 0.4$ & $6.1 \pm 0.5$ \\
\hline
\end{tabular}

linoleic acid (18:2n-6) and $\alpha$-linolenic acid (18:3n-3) (Table 1).

Liver phospholipid fatty acid composition. There were no significant differences in absolute values of liver microsome phospholipid fatty acid composition
(Table 2). The phospholipids from low protein animals tended, however, to have higher levels of docosapentaenoic acid (22:5n-3) (a precursor of 22:6n-3) and lower levels of docosahexaenoic acid (22:6n-3) compared with controls. Hence the ratio of these two fatty acids was reduced $(p<0.05)$ in low protein liver microsome phospholipids (Table 2).

Muscle phospholipid fatty acid composition. The phospholipid fatty acid composition of muscle membranes was not significantly different between control and low protein animals (Table 3 ). As for liver microsomes, muscle phospholipids from low protein animals tended to have higher concentrations of docosapentaenoic acid (22:5n-3, a precursor of 22:6n-3) and lower ones of docosahexaenoic acid (22:6n-3) compared with controls. This meant that the ratio of these two fatty acids was lower in low protein muscle phospholipids (Table 3 ), although this did not reach significance in the number of animals studied $(p=0.059)$.

\section{Discussion}

The object of this study was to explore the possibility that changes in fatty acid phospholipid composition observed in human insulin resistance could have an environmental as opposed to a genetic basis. To address this possibility a rodent model of growth retardation has been used feeding pregnant and lactating rats a low protein diet. Offspring of such rats have been shown to have a greater age-dependent loss of glucose tolerance than controls. In young adult life these low protein offspring, however, have a better glucose tolerance than controls which is associated with increased insulin sensitive glucose uptake into skeletal muscle [11] and adipocytes [12]. In contrast an altered regulation of hepatic glucose output by insulin (similar to that observed in human Type II diabetes, [13]) is present even in young adult low protein offspring [6].

A major finding of this study is the lower hepatic $\Delta 5$ desaturase activity in the low protein offspring. This suggests that a maternal low protein diet can programme the activity of this enzyme in the offspring. This is particularly interesting in light of two previous observations. Firstly the finding that a lower arachidonic acid (20:4n-6): eicosatrienoic acid (20:3n6) ratio (a index of $\Delta 5$ desaturase activity) in muscle phospholipids is related to insulin resistance and secondly that early growth retardation is related to the development of Type II diabetes in adult life. Programming of $\Delta 5$ desaturase in early life is therefore one possible mechanism by which early growth retardation could contribute to the development of Type II diabetes.

Using the fasting plasma insulin concentration as a widely accepted but indirect method of measuring in- 
sulin resistance [1] these results show that the activity of $\Delta 5$ desaturase in low protein offspring is strongly and negatively correlated with insulin concentrations. No such correlation was observed in control animals. The lack of correlation in control animals reflects the possibility that in these animals the activity of this enzyme is high enough for it not to be a dominant factor controlling insulin sensitivity. The correlation in low protein offspring can be interpreted in at least two different ways. Firstly, that insulin regulates the activity of this enzyme in the liver. We have shown previously that the livers of these animals are insulin resistant at least as relates to the action of insulin to inhibit glucagon-stimulated glucose output [6], despite normal or improved glucose tolerance [7]. Therefore, the correlation observed could reflect the degree of insulin resistance of the livers and hence the inability of insulin to increase the activity of the enzyme. The lack of correlation between the fasting insulin concentration and the enzyme activity in control animals argues, however, against this possibility. Secondly, there is a possibility that the reduction of the $\Delta 5$ desaturase activity is a primary and key component of the programming of hepatic metabolism in the offspring of rat dams fed a low protein diet. Using this interpretation it would then follow that a reduced ability to produce certain long chain polyunsaturated fatty acids leads to insulin resistance. This is consistent with observations in humans and experimental animals showing the strong relation between the production or consumption of long chain polyunsaturated fatty acids and insulin sensitivity.

The fatty acid composition of liver phospholipids was similar in both groups. There were no differences in the amount of eicosatrienoic acid (20:3n-6), arachidonic acid (20:4n-6) or in the ratio between the two (a crude index of $\Delta 5$ desaturase activity) in control and low protein offspring. This may at first seem surprising given the difference in measured $\Delta 5$ desaturase activity. Apparent discrepancies between desaturase activities and phospholipid composition have also been reported previously $[14,15]$. This is not unexpected as membrane incorporated arachidonic acid could arise from two sources. Firstly it can be made in vivo from the essential fatty acid linoleic acid $(18: 2 n-6)$ which is present in the diet. The $\Delta 5$ desaturase enzyme is required in this pathway to convert eicosatrienoic acid (20:3n-6) to arachidonic acid (20:4n6). Secondly, arachidonic can be supplied directly from the diet. The offspring in this study were fed a diet containing arachidonic acid. Therefore arachidonic acid could be obtained directly from the diet (i. e. independently of $\Delta 5$ desaturase activity). In low protein hepatic microsomes, the phospholipids tended to have less docosahexaenoic acid (22:6n-3) and more docosapentaenoic acid (22:5n-3). Thus the ratio of the two was reduced in the low protein offspring. The conversion of $22: 5 n-3$ to $22: 6 n-3$ was previously thought to be catalysed by a $\Delta 4$ desaturase enzyme. Recent studies suggest an alternative pathway though where the $22: 5 n-3$ is chain elongated to $24: 5 n-3$ which is subsequently desaturated at position 6 to yield $24: 6 \mathrm{n}-3$. This acid then undergoes partial $\beta$-oxidation to finally yield $22: 6 n-3$ [16]. An analogous pathway has also been suggested for the conversion of $22: 4 n-6$ to $22: 5 n-6$ [17].

This suggests that a maternal low protein diet can programme the ability of the offspring to convert $22: 5 n-3$ to $22: 6 n-3$ as well as $\Delta 5$ desaturase activity. It is not clear at present which stage(s) in the conversion are affected. The decreased conversion of $22: 5 n-3$ to $22: 6 n-3$ is more likely to be reflected in an altered hepatic phospholipid fatty acid composition than the decreased $\Delta 5$ desaturase activity as, unlike the $\Delta 5$ product, docosahexaeneoic acid $(22: 6 \mathrm{n}-3$, a product of $\Delta 4$ desaturase) is not present in the diet. Therefore any docosahexaenoic acid (22:6n-3) incorporated into the phospholipids is dependent on the conversion of 22:5n-3.

The fatty acid composition of muscle phospholipids was also similar in both groups. As in hepatic microsomes the ratio of docosahexaenoic acid to docosapentaenoic acid was reduced, however, in the low protein offspring. It is unclear if there is any $\Delta 5$ desaturase or if conversion of $22: 5 n-3$ to $22: 6 n-3$ occurs in skeletal muscle. It is known that liver is the key site of desaturase activity [18] but it remains to be determined if all desaturation of fatty acids destined for muscle phospholipids occurs there or if some occurs in muscle itself. Docosahexaenoic acid (22:6n-3) is the longest and most highly unsaturated fatty acid found in skeletal muscle. Unless provided in the diet, its precursors must be substantially elongated and desaturated to form this fatty acid. It has been reported that one major difference between the muscle phospholipid composition of Pima Indians (a population with a very high incidence of Type II diabetes) and that of Australians (a largely Caucasian population with a much lower incidence) is the low percentage of docosahexaenoic acid (22:6n-3) in the Pima Indians [3]. This is not thought to reflect a difference in dietary intake as people within the Australian study with little or no discernable n-3 intake had higher muscle docosahexaenoic acid (22:6n-3) concentrations than those of the Pima Indian study group. It was therefore proposed that Pimas have a "genetic reluctance" to incorporate this fatty acid thus predisposing the population to "syndromes of insulin resistance" [3]. The data of our study provides evidence, however, that altered phospholipid fatty acid composition observed in human insulin resistance can have an environmental as opposed to a genetic basis.

The precise mechanism by which changes in fatty acid desauration can alter insulin sensitivity is not clear. It is possible that the effect of poor maternal nutrition and poor fetal growth on insulin sensitivity 
is, at least in part, mediated by a programmed downregulation of key enzymes in the production of prostanoid second messenger(s) which in turn regulate insulin sensitivity. Interestingly, $\mathrm{LTB}_{4}[19]$ and $15 \mathrm{~d}-$ $\mathrm{PGJ}_{2}$ [20] which are arachidonic acid metabolites have been found to have an important role in inflammation and adipogenesis, each by forming complexes with a family of nuclear receptors known as PPARs (Peroxisome Proliferator Activated Receptor). These receptors appear to influence insulin sensitivity as they are targets of insulin sensitizing drugs, the thiazolidinediones [21].

Acknowledgements. We thank D. Hutt, A. Flack, A. Wayman and L. Smith of the Dunn Nutritional Laboratory Animal Unit for their invaluable assistance. We are grateful to Dr. David Pan, Dr. John Prins, Dr. Mick Quigley and Michaela Downie for many helpful discussions. This work was supported by the British Diabetic Association, the Medical Research Council and the Parthenon Trust to whom we give our thanks.

\section{References}

1. Moller DE, Flier JS (1991) Insulin resistance - mechanisms, syndromes and implications. $\mathrm{N}$ Engl $\mathrm{J}$ Med 325(13):938-948

2. Borkman M, Storlien LH, Pan DA, Jenkins AB, Chisholm DJ, Campbell LV (1993) The relationship between insulin sensitivity and the fatty-acid composition of skeletal muscle phospholipids. N Engl J Med 328: 238-244

3. Pan DA, Lilloja S, Milner MR et al. (1995) Skeletal muscle membrane lipid composition is related to adiposity and insulin action. J Clin Invest 96: 2802-2808

4. Philips DIW, Hales CN (1996) The intrauterine environment and susceptibility to non-insulin dependent diabetes and the insulin resistance syndrome; In: Marshall SM, Home PD, Rizza RA (eds) The Diabetes Annual, vol 10. Elsevier, Amsterdam, pp 1-13

5. Hales CN, Barker DJP (1992) Type 2 (non-insulin-dependent) diabetes mellitus: the thrifty phenotype hypothesis. Diabetologia 35: 595-601

6. Ozanne SE, Smith GD, Tikerpae J, Hales CN (1996) Altered regulation of hepatic glucose output in the male offspring of protein malnourished rat dams. Am J Physiol 270:(Endocrinol Metab 33) E559-E564

7. Hales CN, Desai M, Ozanne SE, Crowther NJ (1996) Fishing in the stream of diabetes: from measuring insulin to the control of fetal organogenesis. Biochem Soc Trans 24: $341-350$
8. De Tomas ME, Mercuri O, Rodrigo A (1979) Effects of dietary protein and EFA deficiency on liver $\Delta 5, \Delta 6$ and $\Delta 9$ desaturase activities in the early developing rat. J Nutr 110: 595-599

9. Christiansen EN, Lund JS, Rortveit T, Rustan AC (1991) Effect of dietary n-3 and n- 6 fatty acids on fatty acid desaturation in rat liver. Biochim Biophys Acta 1082: 57-62

10. Folch J, Lees M, Sloane Stanley GH (1957) A simple method for the isolation and purification of total lipids from animal tissues. J Biol Chem 226: 497-509

11. Ozanne SE, Wang CL, Coleman N, Smith GD (1996) Altered muscle insulin sensitivity in the male offspring of protein malnourished rats. Am J Physiol 271: (Endocrinol Metab. 34) E1128-E1134

12. Ozanne SE, Nave BT, Wang CL, Smith GD (1997) Poor fetal nutrition causes long term changes in expression of insulin signalling components in adipocytes. Am J Physiol 273: (Endocrinol. Metab. 36) E46-E51

13. Frank JW, Saslow SB, Camilleri M et al. (1995) Mechanism of accelerated gastric emptying of liquids and hyperglycaemia in patients with Type II Diabetes Mellitus. Gastroenterology 109: 755-765

14. Narce M, Poisson J-P, Belleville J, Chanussot B (1988) Time-course effects of protein malnutrition on hepatic fatty acids $\Delta 6$ and $\Delta 5$ desaturation in the growing rat. $\mathrm{Br} \mathrm{J}$ Nutr 60: 389-402

15. Poisson J-P, Cunnane SC (1991) Long chain fatty acid metabolism in fasting and diabetes: relation between altered desaturase activity and fatty acid composition. J Nutr Biochem 2: 60-70

16. Voss A, Reinhart M, Sankarappa S, Sprecher H (1991) The metabolism of 7, 10,13,16,19-docosapentaenoic acid to 4, $7,10,13,16,19$-docosahexaenoic acid in the rat liver is independent of a 4-desaturase. J Biol Chem 266: 19995-20000

17. Mohammed BS, Sankarappa S, Geiger M, Sprecher H (1995) Re-evaluation of the pathway for the metabolism of 7, 10, 13,16-docosatetraenoic acid to 4, 7, 10, 13, 16- docosapentaenoic acid in rat liver. Arch Biochem Biophys 317: $179-184$

18. Hrelia S, Lopez Jimenez JA, Bordoni A et al. (1995) Essential fatty acid metabolism in cultured rat cardiomyocytes in response to either N-6 or N-3 fatty acid supplementation. Biochem Biophys Res Commun 216: 11-19

19. Devchand PR, Keller H, Peters JM et al. (1996) The PPARa-leukotriene $\mathrm{B}_{4}$ pathway to inflammation control. Nature 384: 39-43

20. Forman BM, Tontonoz P, Chen J et al. (1995) 15-Deoxy$\Delta^{12,14}$-Prostaglandin $\mathrm{J}_{2}$ is a ligand for the adipocyte determination factor PPAR $\gamma$. Cell 83: 803-812

21. Saltiel AR, Olefsky JM (1996) Thiazolidinediones in the treatment of insulin resistance and type II diabetes. Diabetes 45: 1661-1669 